\title{
PENERAPAN FUZZY EXPERT SYSTEM UNTUK DIAGNOSA PENYAKIT TELINGA, HIDUNG DAN TENGGOROKAN BERBASIS ANDROID
}

\author{
Mansuri $^{1}$, Rury Retno Kartika ${ }^{2}$ \\ 1Ilmu Komputer, Fakultas Ilmu Komputer \\ Universitas Borobudur, Jakarta, Indonesia \\ e-mail:mansuri@borobudur.ac.id \\ ${ }^{2}$ Teknik Informatika, Fakultas Teknik \\ Universitas Maarif Hasyim Latif, Sidoarjo, Indonesia \\ e-mail: ruryretno@gmail.com \\ Diterima: 15 Oktober 2020. Disetujui : 23 Desember 2020. Dipublikasikan : 30 Desember 2020

\begin{abstract}
ABSTRAK
Meningkatnya perkembangan teknologi saat ini, salah satunya teknologi mobile atau smartphone, hal ini tidak bisa dipungkiri bahwa kehidupan manusia dengan perangkat mobile sudah melekat. Dengan adanya sistem operasi dalam smartphone, salah satunya sistem operasi android yang digunakan oleh teknologi mobile yang dapat membantu pekerjaan manusia Penelitian ini bertujuan untuk merancang aplikasi sistem pakar diagnose penyakit THT berbasis android dengan metode Fuzzy Logic. Dengan aplikasi ini dapat memeberikan informasi lebih cepat untuk mengetahui maslah yang terjadi pada bagian telinga, hidung, dan tenggorokan. Aplikasi ini juga dapat memberikan solusi yang terbaik dalam menentukan penanganan sesuai dengan diagnosa yang telah diketahui. Dengan adanya aplikasi ini pengguna layaknya seperti berhadapan dengan dokter langsung, jadi pengguna bisa mendapatkan penanganan yang lebih cepat tanpa harus memakan waktu untuk menemui dokter
\end{abstract}

Kata kunci : fuzzy logic, diagnosa penyakit tht, kesehatan, penyakit, android

\section{PENDAHULUAN}

Meningkatnya perkembangan teknologi saat ini, salah satunya teknologi mobile atau smartphone, hal ini tidak bisa dipungkiri bahwa kehidupan manusia dengan perangkat mobile sudah melekat.

Dengan adanya sistem operasi dalam smartphone, salah satunya sistem operasi android yang digunakan oleh teknologi mobile yang dapat membantu pekerjaan manusia. Telepon genggam yang di masa lalu hanya bisa digunakan untuk telepon dan sms saja kini berubah menjadi sebuah komputer dalam genggaman. Hampir semua orang menjadikan smartphone sebagai pengganti komputer, sehingga smartphone saat ini menjadi sarana penunjang pekerjaan karena sistem operasi mobile kini telah memungkinkan untuk membuat aplikasi yang lebih canggih.

Penyakit THT adalah masalah kesehatan masyarakat, karena terjadi mengenal musim. Penyakit ini bisa menyerang berbagai usia. Gangguan THT tersebut akan mudah diatasi atau disembuhkan ketika masih dalam kondisi tahap awal. Saat ini, untuk mengetahui diangnosa THT harus bertemu dengan dokter, sehingga tidak menutup kemungkinan untuk melakukan kesalahan diagnosa dan dapat mempermudah masyarakat mengetahui penyakit yang dialaminya.

Pembuatan sebuah aplikasi sistem pakar agar dapat meminimalisir kesalahan diagnose maka perlu bantuan perniruan kerja dari para ahli. Maka dengan perkembangan teknologi yang semakin pesat ini dapat dimanfaatkan untuk membantu tenaga medis, misalnya mendiagnosa gejala-gejala penyakit THT pada pasien. Dengan adanya Aplikasi sistem pakar diagnosa THT ini, orang awam yang tidak tahu tentang gangguan/masalah yang terjadi pada telinga, hidung, dan tenggorokannya akan dapat dibantu dalam mendeteksi penyakitnya bagaikan konsultasi pada dokter.

Pencegahan penyakit dapat dilakukan dengan cepat, bahkan dapat dilakukan pencegahan penyakit tertentu. Dan dengan adanya solusi ini pengguna yang benar-benar tidak tahu sekalipun tentang ilmu kesehatan akan terbantu untuk pengambilan keputusan selanjutnya dalam hal pemeriksaannya, dan bisa memilih obat yang tepat nantinya sesuai gejala yang sudah diketahui. 


\section{METODE PENELITIAN}

Metode yang digunakan pada penelitian ini adalah metode deskriptif. Dengan metode ini, data yang disimpulkan akan disusun, dianalisa, dijelaskan dan diimplementasikan pada perangkat lunak

\section{Tahap Pengembangan Perangkat Lunak}

Penulis menggunakan metode Waterfall dalam tahap pengembangan perangkat lunaknya, sebagaimana pada Gambar 1. Berikut beberapa tahapan yang digunakan metode waterfall:

1. Pengumpulan data

Pengumpulan data dari berbagai sumber. Seperti pada buku, jurnal, internet dan sebagainya.

2. Analisis

Menganalisis dari rumusan masalah dan batasan masalah, dengan ini masalah dapat diketahui dan dapat dipecahkan.

3. Perancangan sistem

Tahap ini yang harus diperhatikan sangat detail agar aplikasi mempunyai daya tarik.

4. Pengkodean

Tahap ini dilakukan menggunakan bahasa pemrograman.

5. Pengujian

Tahap ini dilakukan untuk mengetahui aplikasi sudah berjalan dengan sempurna atau masih ada yang perlu diperbaiki.

6. Pemeliharaan

Aplikasi perlu dipelihara agar dapat berjalan dengan baik. Adanya error juga bisa saja terjadi dikarenakan lingkungan sistem dan sebagainya.

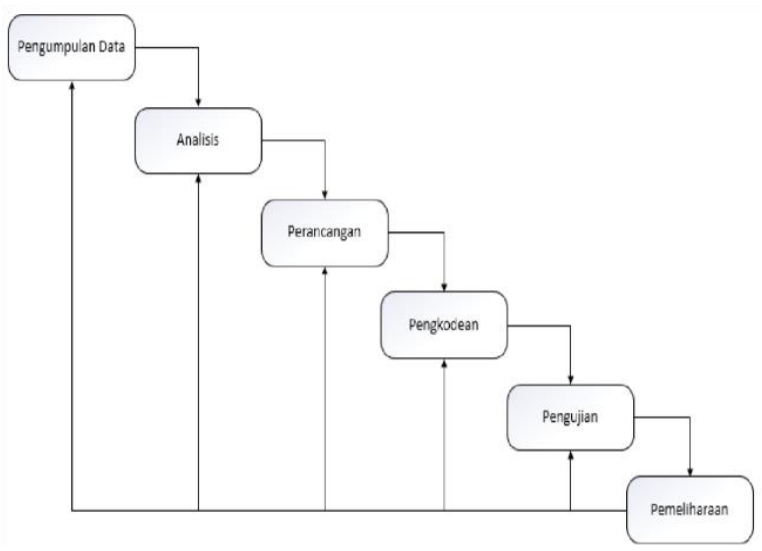

Gambar 1. Metode Waterfall

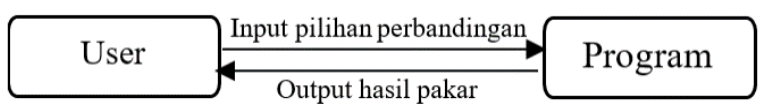

Gambar 2. Alur interaksi sistem dengan pengguna

\section{Perencanaan Sistem}

Sistem pakar sering digunakan untuk masalah yang kompleks dan rumit dipecahkan. Konsep dasar dari alur interaksi sistem/program dengan pengguna/user pada Gambar 2.

Berikut pada Tabel 1 adalah beberapa contoh data gejala dan nama penyakit pada gangguan THT. Dan pada Tabel 2 adalah daftar nama penyakit beserta kategori dan kode penyakitnya. Dan pada Tabel 3 adalah daftar bobot penyakit telinga luar.

Tabel 1. Daftar Contoh Gejala

\begin{tabular}{c|l}
\hline Kode Gejala & \multicolumn{1}{|c}{ Gejala } \\
\hline G1 & Nyeri Tenggorokan \\
\hline G2 & Batuk \\
\hline G3 & Suara Serak \\
\hline G4 & Pusing \\
\hline G5 & Demam \\
\hline G6 & Bersin \\
\hline G7 & Hidung Tersumbat \\
\hline G8 & Nyeri Otot Leher \\
\hline G9 & Radang Tenggorokan \\
\hline G10 & Sakit Saat Menelan \\
\hline G11 & Mimisan \\
\hline G12 & Sakit Kepala \\
\hline G13 & Fungsi Indera Penciuman Menurun \\
\hline G14 & Muntah \\
\hline G15 & Nyeri Bila Pinggiran Hidung Ditekan \\
\hline G16 & Nyeri Di Telinga \\
\hline G17 & Saluran Telinga Tersumbat \\
\hline G18 & Telinga Gatal-Gatal \\
\hline G19 & Keluar Cairan Berbau Dari Telinga \\
\hline G20 & Telinga Berdenging
\end{tabular}

\begin{tabular}{|c|c|c|}
\hline Kategori & $\begin{array}{c}\text { Kode } \\
\text { Penyakit }\end{array}$ & Nama Penyakit \\
\hline \multirow{4}{*}{$\begin{array}{l}\text { Telinga } \\
\text { Luar }\end{array}$} & P1 & Penyumbatan Telinga Luar \\
\hline & $\mathrm{P} 2$ & Infeksi Telinga Luar \\
\hline & P3 & Cedera Telinga Luar \\
\hline & $\mathrm{P} 4$ & Tumor Telinga Luar \\
\hline \multirow{4}{*}{$\begin{array}{c}\text { Telinga } \\
\text { Dalam dan } \\
\text { Tengah }\end{array}$} & P5 & Otitis Media Akut \\
\hline & P6 & Infeksi Saluran Telinga \\
\hline & P7 & Tinnitus \\
\hline & P8 & Miringitis \\
\hline \multirow{4}{*}{ Hidung } & P9 & Sinusitis \\
\hline & P10 & Patah Tulang Hidung \\
\hline & P11 & Deviasi Septum \\
\hline & P12 & Perforasi Septum \\
\hline \multirow{4}{*}{$\begin{array}{c}\text { Tenggorok } \\
\text { an }\end{array}$} & $\mathrm{P} 13$ & Faringitis \\
\hline & P14 & Laringitis \\
\hline & P15 & Polip Pita Suara \\
\hline & P16 & Kelumpuhan Pita Suara \\
\hline
\end{tabular}

Tabel 3 Daftar Bobot Penyakit Telinga Luar

\begin{tabular}{|c|c|c|c|c|c|}
\hline \multicolumn{2}{|r|}{ TELINGA LUAR } & P1 & $\mathrm{P} 2$ & P3 & $\mathrm{P} 4$ \\
\hline G1 & Telinga tersumbat & 5 & 5 & 0 & 5 \\
\hline G2 & Telinga gatal-gatal & 4 & 1 & 0 & 0 \\
\hline G3 & Nyeri di telinga & 5 & 5 & 1 & 1 \\
\hline G4 & Tuli (sementara) & 5 & 0 & 0 & 3 \\
\hline G5 & $\begin{array}{l}\text { Keluar cairan berbau } \\
\text { busuk dari telinga }\end{array}$ & 0 & 5 & 0 & 1 \\
\hline G6 & Telinga memar & 1 & 2 & 5 & 0 \\
\hline G7 & $\begin{array}{l}\text { Terjadi perubahan bentuk } \\
\text { telinga }\end{array}$ & 0 & 0 & 5 & 0 \\
\hline G8 & $\begin{array}{l}\text { Terdapat robekan pada } \\
\text { telinga }\end{array}$ & 0 & 1 & 5 & 0 \\
\hline G9 & $\begin{array}{l}\text { Patah tulang disekitar } \\
\text { saluran telinga }\end{array}$ & 0 & 0 & 5 & 0 \\
\hline G10 & $\begin{array}{l}\text { Banyak kotoran telinga } \\
\text { tertimbun }\end{array}$ & 2 & 0 & 0 & 5 \\
\hline G11 & Pendengaran hilang & 1 & 0 & 0 & 5 \\
\hline
\end{tabular}


Berikut pada Tabel 4 adalah daftar bobot penyakit telinga dalam dan tengah. Dan pada Tabel 5 adalah daftar bobot penyakit hidung. Serta pada Tabel 6 adalah daftar bobot penyakit tenggorokan.

\begin{tabular}{l|l|l|l|l|l} 
Tabel 4. Daftar bobot penyakit telinga dalam tengah \\
\hline \multicolumn{2}{|l|}{ TELINGA DALAM DAN TENGAH } & P1 & P2 & P3 & P4 \\
\hline G1 & $\begin{array}{l}\text { Sakit telinga yang berat dan } \\
\text { menetap }\end{array}$ & 5 & 0 & 0 & 0 \\
\hline G2 & $\begin{array}{l}\text { Gangguan pendengaran } \\
\text { (sementara) }\end{array}$ & 5 & 3 & 1 & 4 \\
\hline G3 & Mual & 5 & 0 & 0 & 0 \\
\hline G4 & Muntah & 5 & 0 & 0 & 0 \\
\hline G5 & Diare & 5 & 0 & 0 & 0 \\
\hline G6 & Demam tinggi sampai 40,05ㄷ & 5 & 0 & 0 & 0 \\
\hline G7 & $\begin{array}{l}\text { Pada gendang telinga terdapat } \\
\text { lepuhan-lepuhan berisi cairan }\end{array}$ & 0 & 5 & 0 & 1 \\
\hline G8 & $\begin{array}{l}\text { Nyeri muncul secara tiba-tiba dan } \\
\text { berlangsung selama 24-48 jam }\end{array}$ & 1 & 5 & 0 & 1 \\
\hline G9 & Demam & 3 & 5 & 0 & 0 \\
\hline G10 & Pendengaran hilang & 1 & 5 & 0 & 1 \\
\hline G11 & $\begin{array}{l}\text { Suara gaduh seperti berdengung, } \\
\text { berdering, bersiul dan berdesis }\end{array}$ & 0 & 0 & 5 & 0 \\
\hline G12 & $\begin{array}{l}\text { Suara gaduh terdengar saat hendak } \\
\text { tidur }\end{array}$ & 0 & 0 & 5 & 0 \\
\hline G13 & Gatal & 2 & 0 & 0 & 5 \\
\hline G14 & Sakit & 2 & 1 & 1 & 5 \\
\hline G15 & $\begin{array}{l}\text { Keluar cairan berbau busuk dari } \\
\text { telinga }\end{array}$ & 0 & 0 & 0 & 5 \\
\hline G16 & Terdapat bisul & 0 & 0 & 0 & 5 \\
\hline
\end{tabular}

Tabel 5. Daftar Bobot Penyakit Hidung

\begin{tabular}{|c|c|c|c|c|c|}
\hline & HIDUNG & P1 & P2 & P3 & $\mathrm{P} 4$ \\
\hline G1 & Sakit kepala ketika bangun pagi & 5 & 0 & 3 & 0 \\
\hline G2 & Tidak enak badan & 4 & 1 & 1 & 1 \\
\hline G3 & Demam & 4 & 0 & 0 & 0 \\
\hline G4 & Letih Lesu & 4 & 1 & 1 & 0 \\
\hline G5 & Batuk & 4 & 0 & 0 & 0 \\
\hline G6 & Hidung tersumbat & 5 & 2 & 5 & 1 \\
\hline G7 & $\begin{array}{l}\text { Nyeri pipi tepat dibawah mata, sakit } \\
\text { gigi dan sakit kepala }\end{array}$ & 4 & 0 & 1 & 0 \\
\hline G8 & Sakit kepala di dahi & 5 & 0 & 0 & 0 \\
\hline G9 & Nyeri dibelakang dan diantara mata & 4 & 0 & 0 & 0 \\
\hline G10 & Nyeri bila pinggiran hidung ditekan & 4 & 3 & 1 & 3 \\
\hline G12 & $\begin{array}{l}\text { Nyeri di lokasi yang tidak dapat } \\
\text { dipastikan, bisa dirasakan dipuncak } \\
\text { kepala bagian depan/belakang }\end{array}$ & 3 & 2 & 1 & 3 \\
\hline G13 & Sakit/nyeri telinga & 3 & 0 & 0 & 0 \\
\hline G14 & Sakit/nyeri leher & 3 & 0 & 0 & 0 \\
\hline G15 & Nyeri di hidung & 2 & 5 & 2 & 1 \\
\hline G16 & Pendarahan hidung & 0 & 5 & 5 & 0 \\
\hline G17 & Memar disekeliling mata & 0 & 5 & 0 & 0 \\
\hline G18 & Kelainan bentuk hidung & 0 & 5 & 0 & 0 \\
\hline G19 & Pembengkakan pada hidung & 1 & 5 & 0 & 0 \\
\hline G20 & $\begin{array}{l}\text { Gangguan menghirup udara melalui } \\
\text { hidung }\end{array}$ & 3 & 5 & 4 & 2 \\
\hline G21 & Pendarahan hidung berulang & 0 & 2 & 2 & 0 \\
\hline G22 & Nyeri wajah & 0 & 0 & 5 & 0 \\
\hline G23 & Sakit kepala & 2 & 1 & 5 & 0 \\
\hline G24 & $\begin{array}{l}\text { Mendengkur ketika tidur (pada anak- } \\
\text { anak dan bayi) }\end{array}$ & 0 & 0 & 5 & 0 \\
\hline G25 & Terbentuknya keropeng & 0 & 0 & 0 & 5 \\
\hline G26 & Nyeri jika ujung/sayap hidung ditekan & 3 & 3 & 1 & 5 \\
\hline
\end{tabular}

Tabel 6. Daftar Bobot Penyakit Tenggorokan

\begin{tabular}{c|l|c|c|c|c}
\hline \multicolumn{2}{|c}{ TENGGOROKAN } & P1 & P2 & P3 & P4 \\
\hline G1 & Nyeri tenggorokan & 5 & 3 & 1 & 3 \\
\hline G2 & Nyeri menelan & 5 & 3 & 0 & 1 \\
\hline G3 & Demam & 5 & 5 & 0 & 0 \\
\hline G4 & Terjadinya perubahan suara & 0 & 5 & 3 & 3 \\
\hline \multirow{2}{*}{ G5 } & $\begin{array}{l}\text { Tenggorokan terasa gatal \& } \\
\text { tidak nyaman }\end{array}$ & 2 & 5 & 2 & 3 \\
\hline G6 & Tidak enak badan & 2 & 2 & 0 & 1 \\
\hline G7 & Kesulitan menelan & 3 & 5 & 0 & 4 \\
\hline G8 & Sakit tenggorokan & 1 & 5 & 1 & 1 \\
\hline G9 & Gangguan pernapasan & 0 & 4 & 1 & 5 \\
\hline G10 & Suara serak & 0 & 3 & 5 & 5 \\
\hline G11 & Kekuatan suara berkurang & 0 & 2 & 2 & 5 \\
\hline
\end{tabular}

\section{Use Case Diagram}

Beberapa hal yang dapat dilakukan oleh pengguna/user kepada sistem bisa dilihat pada Use Case Diagram pada Gambar 3.

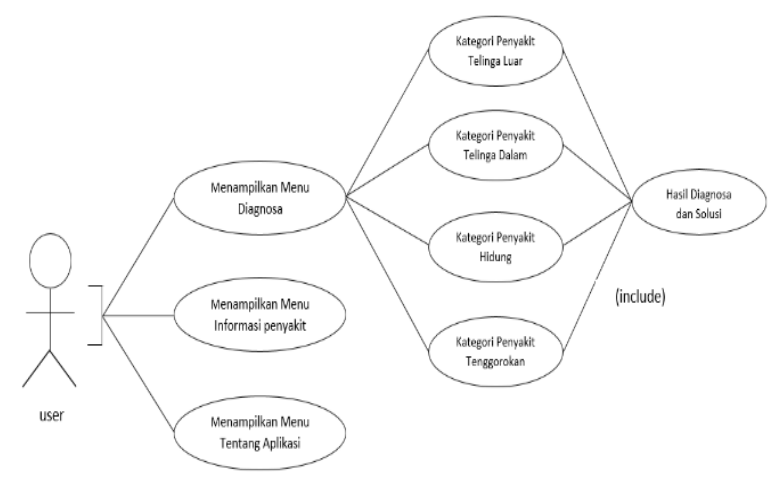

Gambar 3. Use Case Diagram

\section{Flowchart}

Pada penelitian ini diagram alir sistem aplikasi tentang pilihan diagnosa dapat dilihat pada Gambar 3.

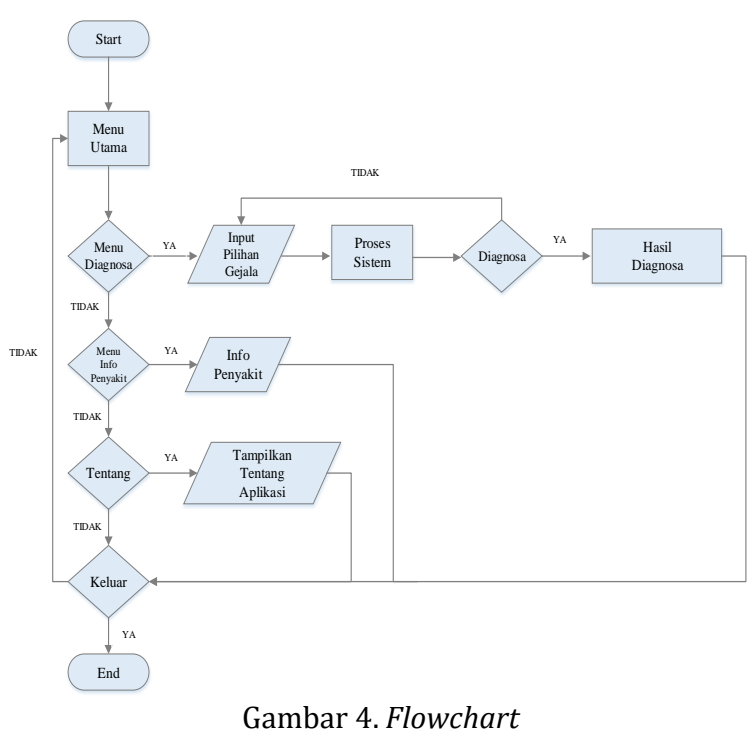

Activity Diagram

Activity Diagram merupakan diagram yang memodelkan aliran kerja dari urutan setiap aktifitas dalam suatu proses yang mengacu pada 
Use Case Diagram. Untuk lebih jelasnya dapat dilihat pada Gambar 5.

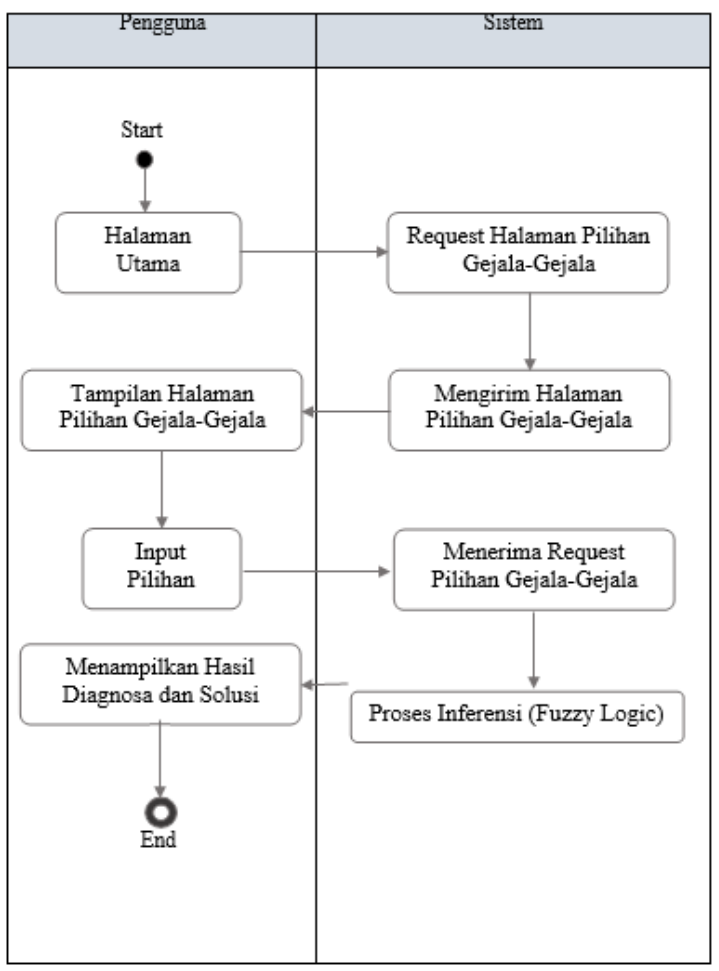

Gambar 5. Activity Diagram

\section{Squence diagram}

Sequence diagram bertujuan untuk menggambarkan perilaku pada sebuah skenario dan dideskripsikan bagaimana sistem berinteraksi. Untuk lebih jelasnya dapat dilihat pada Gambar 6.

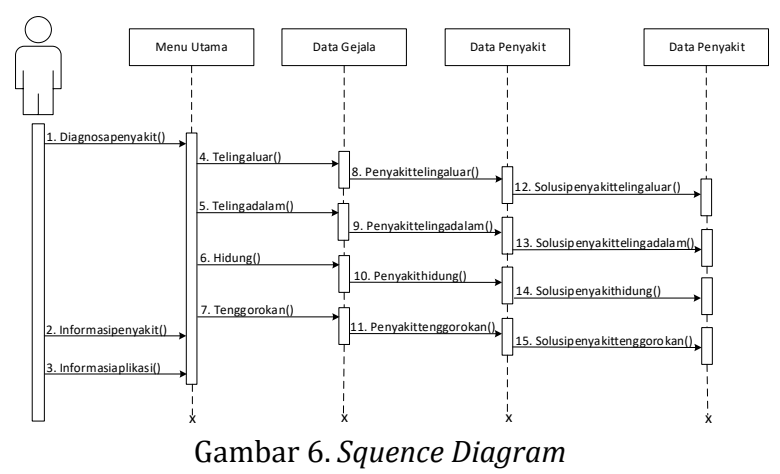

IMPLEMENTASI DAN PEMBAHASAN

\section{Implementasi Sistem}

Tahap ini merupakan kegiatan pembuatan aplikasi dengan menggunakan bantuan perangkat lunak sesuai dengan analisis dan perancangan untuk menghasilkan suatu sistem. Sistem kemudian diimplementasikan menggunakan Android Studio untuk pengolahan kode program. Disini akan dijelaskan mengenai cara menjalankan program dengan benar.

\section{Tampilan Antarmuka (User Interface)}

1. Pada halaman utama (home) user akan dihadapkan pada halaman ini yang terdapat 3 button seperti pada Gambar 7.

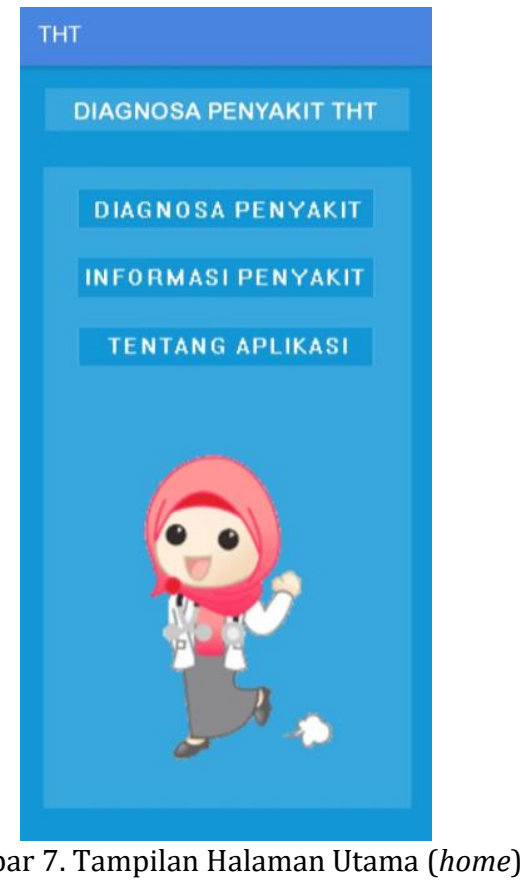

2. Selanjutnya pada menu diagnosa penyakit, terdapat 4 kategori pilihan penyakit. Untuk lebih jelasnya dapat dilihat pada Gambar 8.

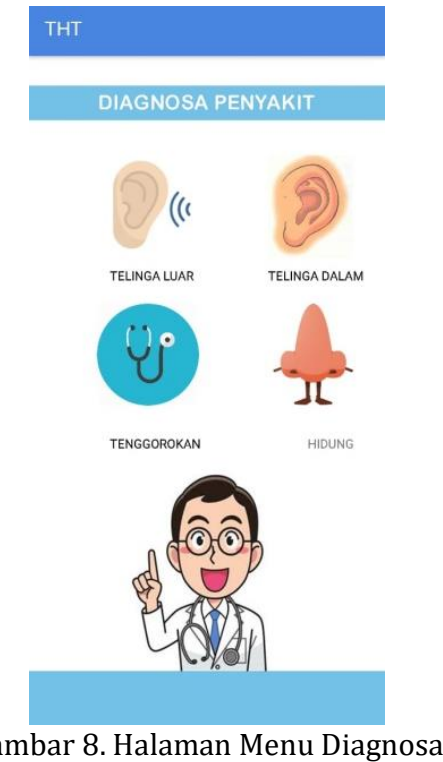

3. Berikutnya adalah menu pilihan gejala. Dalam tampilan ini pengguna dapat memilih gejalagejala sesuai yang sedang dialami, dengan cara mencentang pilihan-pilihan gejala yang telah ditampilkan, Untuk tampilan menu pilihan gejala dapat dilihat pada Gambar 9.

4. Selanjutnya adalah halaman hasil diagnosa. Pada halaman ini menampilkan nama penyakit 
beserta persentase dan solusinya. Untuk lebih jelasnya dapat dilihat pada Gambar 10.

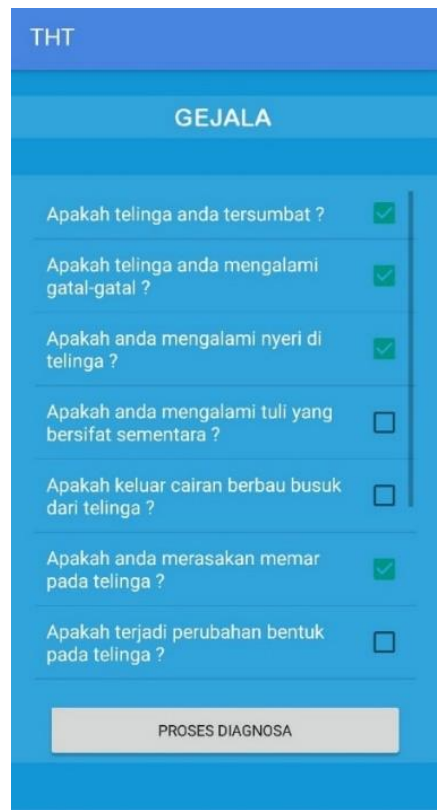

Gambar 9. Tampilan Menu Pilihan Gejala

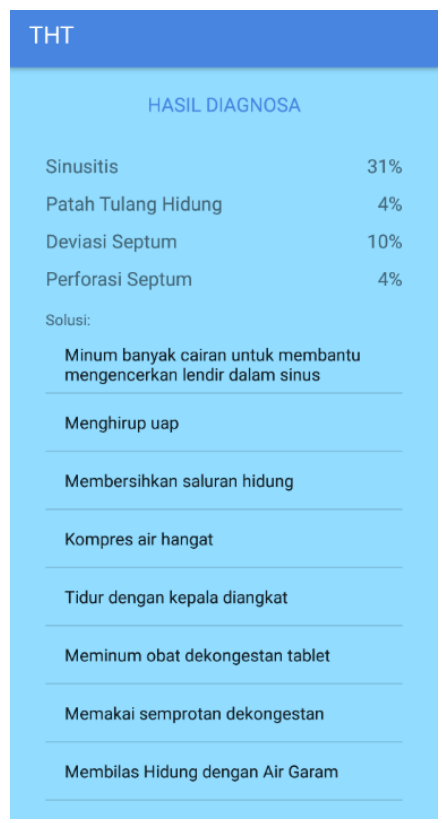

Gambar 10. Tampilan Hasil Diagnosa

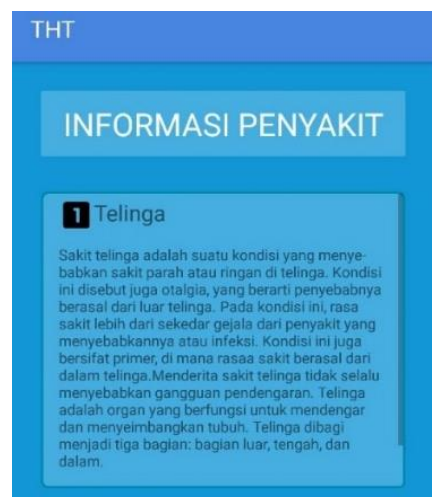

Gambar 11. Tampilan Informasi Penyakit
5. Menu imformasi penyakit menu ini terdapat pada halaman utama. Pada halaman ini pengguna dapat mengetahui tentang informasi penyakit untuk lebih jelasnya dapat dilihat pada Gambar 11.

6. Terakhir pada halaman tentang aplikasi, pada tampilan ini pengguna dapat mengetahui informasi tentang aplikasi sistem diagnosa penyakit THT yang sedang digunakan. Untuk lebih jelasnya dapat dilihat pada Gambar 12.

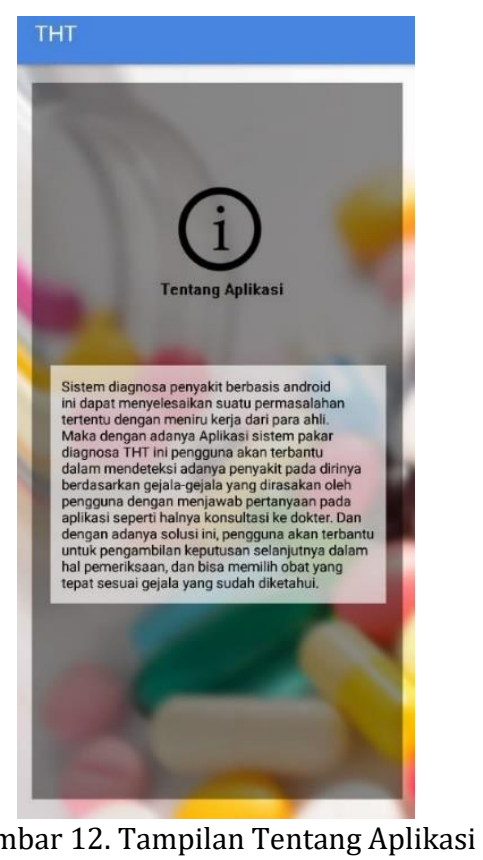

Untuk menghitung nilai akurasi dari sistem ini maka penulis melakukan uji coba sebanyak 5 kali terhadap sistem yang telah dibangun, setiap uji coba akan dilakukan dengan menampilkan nilai dari hasil diagnosa penyakit. Disini dilakukan perhitungan dengan membandingkan antara perhitungan sistem dan perhitungan manual, berikut contoh uji coba yang dilakukan dengan menggunakan perhitungan manual. Berikut hasil perhitungan 5 kali percobaan :

$$
\begin{aligned}
& \mathrm{P} 01=\frac{5+5+0+2}{23} \times 100=\frac{12}{23} \times 100=52 \\
& \mathrm{P} 02=\frac{5+5+0+0}{19} \times 100=\frac{10}{19} \times 100=52 \\
& \mathrm{P} 03=\frac{5+5+0+2}{21} \times 100=\frac{12}{21} \times 100=29 \\
& \mathrm{P} 04=\frac{5+5+0+2}{20} \times 100=\frac{12}{20} \times 100=55
\end{aligned}
$$

Contoh perbandingan uji akurasi Perhitungan telinga luar antara aplikasi dengan perhitungan manual seperti pada Tabel 7 . 
Tabel 7. Perbandingan Perhitungan Telinga Luar

\begin{tabular}{|c|c|c|c|c|c|c|c|c|c|}
\hline \multirow{2}{*}{ NO } & \multirow{2}{*}{$\begin{array}{c}\text { GEJALA YANG } \\
\text { DIPILIH }\end{array}$} & \multicolumn{4}{|c|}{ HASIL PERHITUNGAN } & \multicolumn{4}{c|}{ HASIL PERHITUNGAN } \\
\cline { 3 - 10 } & P1 & P2 & P3 & P4 & P1 & P2 & P3 & P4 \\
\hline 1 & $\begin{array}{c}\text { G01, G03, G09, } \\
\text { G10 }\end{array}$ & 52 & 52 & 29 & 55 & 52 & 53 & 29 & 55 \\
\hline 2 & $\begin{array}{c}\text { G03, G04, G06, } \\
\text { G10 }\end{array}$ & 57 & 37 & 29 & 45 & 57 & 37 & 29 & 45 \\
\hline 3 & $\begin{array}{c}\text { G01, G02, G03, } \\
\text { G04, G05 }\end{array}$ & 83 & 84 & 5 & 50 & 83 & 84 & 5 & 50 \\
\hline 4 & $\begin{array}{c}\text { G08, G09, G10, } \\
\text { G11 }\end{array}$ & 13 & 5 & 48 & 50 & 13 & 5 & 48 & 50 \\
\hline 5 & $\begin{array}{c}\text { G02, G03, G05, } \\
\text { G06, G07 }\end{array}$ & 43 & 68 & 52 & 10 & 43 & 68 & 52 & 10 \\
\hline
\end{tabular}

\section{PENUTUP}

Rancangan sistem yang dibuat berhasil dalam mendiagnosa penyakit THT sesuai dengan fungsi dan kegunaan. Perancangan sistem pakar ini dibuat berbasis Android yang tentunya lebih memudahkan pengguna dalam mendiagnosa gangguan penyakit pada telinga, hidung, dan tenggorokan tanpa harus menunggu konsultasi dengan dokter.

Untuk tahap pengembangan penelitian sistem ini antara lain: (1) melakukan pengembangan agar aplikasi bisa terintegrasi dengan baik menggunakan konsep metode, basis data dan bahasa pemrograman yang lain; (2) melakukan pengembangan terhadap jumlah penyakit yang di diagnosa agar sistem lebih kompleks; (3) penambahan nama dokter pakar atau refrensi lainnya; dan (4) melakukan pengembangan pada desain interaktif agar pengguna lebih tertarik dan lebih mudah menggunakan aplikasi ini.

\section{DAFTAR PUSTAKA}

Abrori, M., \& Primahayu, A. H. (2016). Aplikasi Logika Fuzzy Metode Mamdani Dalam Pengambilan Keputusan Penentuan Jumlah Produksi. Kaunia: Integration and Interconnection Islam and Science, 11(2), 9199.

Nurhayati, H., \& Nugroho, F. (2012). Implementasi Fuzzy Expert System Untuk Diagnosis Penyakit Jantung. Prosiding Seminas, 1(2). Retrieved from http://journal.unipdu.ac.id:8080/index.php /seminas/article/view/212
Putra, P. A. D., Purnawan, I. K. A., \& Putri, D. P. S. (2018). Sistem Pakar Diagnosa Penyakit Mata dengan Fuzzy Logic dan Naïve Bayes. MERPATI, 6(1).

Santoso, L. W., Intan, R., \& Sugianto, F. (2008). IMPLEMENTASI FUZZY EXPERT SYSTEM UNTUK ANALISA PENYAKIT DALAM PADA MANUSIA. Seminar Nasional Aplikasi Teknologi Informasi, 1(1), 1907-5022. Retrieved from https://journal.uii.ac.id/Snati/article/view/ 723

Wiyanti, D. T., \& Agustin, E. W. (2016). Sistem Pakar Diagnosa Kulit untuk Menentukan Kosmetik Perawatan Wajah dengan Metode Certainty Factor dan Fuzzy Logic. Seminar Nasional Ilmu Komputer (SNIK 2016). 